University of South Carolina

Scholar Commons

Summer 1994

\title{
The Answering Machine Generation - Who Are They and What Problem Do They Pose for Survey Research
}

Robert W. Oldendick

University of South Carolina - Columbia, oldendick-bob@sc.edu

Michael W. Link

University of South Carolina - Columbia, michael.link@nielsen.com

Follow this and additional works at: https://scholarcommons.sc.edu/poli_facpub

Part of the Communication Commons, and the Political Science Commons

\section{Publication Info}

Published in Public Opinion Quarterly, Volume 58, Issue 2, Summer 1994, pages 264-273.

http://poq.oxfordjournals.org/?code=poq\&homepage.x=82\&homepage.y=7\&.cgifields=code

(C) 1994 by Oxford University Press

This Article is brought to you by the Political Science, Department of at Scholar Commons. It has been accepted for inclusion in Faculty Publications by an authorized administrator of Scholar Commons. For more information, please contact digres@mailbox.sc.edu. 


\title{
THE ANSWERING MACHINE GENERATION \\ WHO ARE THEY AND WHAT PROBLEM DO THEY POSE FOR SURVEY RESEARCH?
}

\author{
ROBERT W. OLDENDICK \\ Institute of Public Affairs, University of South Carolina \\ MICHAEL W. LINK \\ Institute of Public Affairs, University of South Carolina
}

\begin{abstract}
Increased incidence of telephone answering machines and the use of such devices to screen calls pose a potential threat to the representativeness of samples in telephone surveys. Using data from nine statewide surveys, this analysis examines the extent to which answering machines are used to screen calls and the demographic characteristics associated with answering machine use and call screening. Results show that at most two to three percent of households use answering machines to screen calls, and that such screening is more likely to take place in households with higher family incomes, outside rural areas, and which include individuals who are younger and have higher levels of education. While call screening does not presently threaten the representativeness of samples in telephone surveys, the increased incidence of answering machines together with the increased percentage of households indicating these devices are sometimes used to screen calls demonstrate that the potential bias from this source is growing.
\end{abstract}

Although there are many potential sources of error in surveys, among the most disturbing are those that threaten the representativeness of the sample. Lack of representativeness resulting from noncoverage, refusals to participate, or other forms of nonresponse jeopardize the accuracy of survey results. In this study we address one aspect of this problem by examining the extent to which the increased use of tele-

This research was supported, in part, by an award from the University of South Carolina's Research and Productive Scholarship Fund. The authors would like to thank the anonymous referees who supplied many valuable suggestions.

Public Opinion Quarterly Volume 58:264-273 @ 1994 by the American Association for Public Opinion Research All rights reserved. 0033-362X/94/5802-0007\$02.50 
phone answering machines may be contributing to declining response rates.

Previous work in this area has focused primarily upon the incidence of answering machines (Baumgartner 1990; Tuckel and Feinberg 1991), strategies for contacting these households (Piazza 1993; Piekarski 1990), and demographic correlates associated with answering machine use (Oldendick 1993). Most of this research indicates that, although a significant percentage of households have such machines, a substantial proportion of these households are nonetheless accessible to survey researchers.

The current investigation extends this research by examining trends in answering machine use and by exploring more extensively the correlates of both answering machine ownership and the use of these machines to screen calls.

\section{Data and Methods}

The data come from nine random digit dialed telephone surveys of the adult (18 and over) population in South Carolina. Respondents within households were selected using the last birthday method (Oldendick et al. 1988; O'Rourke and Blair 1983). Households were contacted a minimum of six times before a final disposition was assigned. Senior interviewers recontacted households in which an interview was initially refused in an attempt to obtain a completed interview. After two refusals, no additional contacts were made. The surveys were conducted between November 1989 and November 1992 and covered issues such as public transportation, state budget priorities and taxes, race relations, the environment, and the arts. ${ }^{1}$

The prevalence of telephone answering machines was estimated in two ways. First, telephone numbers that produced any contact with an answering machine were tracked to determine whether they resulted in completed interviews, were never contacted, or were otherwise disposed. Second, the final questions in each of these surveys were (1) "Does your household have a telephone answering machine?" and, for those households that reported having one, (2) "Does anyone in your household ever use this telephone answering machine to screen unwanted calls?"

1. Response rates for these surveys ranged from 60.2 percent for the September 1990 survey to 66.5 percent for the one conducted in March 1990. Response rates were calculated by dividing the total number of completions + partial completions by the number of completions + partial completions + refusals + ill/senile/not available during fielding period + the estimated number of households among the never answered numbers. 


\section{Prevalence of Answering Devices: The Potential Problem}

Previous studies have estimated the incidence of answering machines in households nationally to be approximately 25 percent (Parsley 1992; Piekarski 1990; Tuckel and Feinberg 1991). ${ }^{2}$ As Tuckel and Feinberg (1991, p. 205) explain, in estimating the accessibility of these households it is important to examine the difference between "the observed frequency of telephone answering machines as a response disposition and the frequency we would expect if all answering machine owners were to use their machines to the maximum extent." Following their lead, we begin with the final dispositions of the sampled numbers for each survey.

Table 1 presents the percentage of calls resulting in a final "answering machine" disposition-that is, each time these numbers were dialed they went unanswered or reached an answering machine. While this outcome shows a slight tendency to increase over time, the variation is not statistically significant. Overall, call attempts resulted in either consistent answering machine contacts or a combination of answering machines and "no answers" about 2.5 percent of the time. At most, then, about 2 percent of households may be using a telephone answering machine to screen calls on a consistent basis. ${ }^{3}$

\section{Self-Reports of Answering Machine Ownership and Screening}

While the use of answering machines to screen calls may not be a major problem at present, other data show that both answering machine ownership and screening-at least of a sporadic nature-are increasing. Table 2 shows that the incidence of self-reported ownership of these machines in South Carolina has increased from 25 percent in 1989 to approximately 40 percent in 1992 . More important, there has

2. A more recent estimate places this figure at more than 43 percent (Electronic Industries Association 1991).

3. This figure is somewhat lower than the 5.7 percent reported by Tuckel and Feinberg (1991, pp. 206-7). While part of this difference may result from the fact that their study involved a different population, it is more likely a result of the use of alternative procedures. In their study, most households were called a maximum of three times, while in the surveys reported here numbers were attempted a minimum of six times. In addition, unlike our study, their "answering machine" disposition included not only consistent answering machine contacts, but also those cases in which a number yielded a callback followed by an answering machine on a subsequent call. Our estimate of 2 percent is an upper bound in that not all these households may be "screening" calls, in the sense that someone is at home, but using the answering device to determine who is calling; there are likely to be instances in which no one was available at the times we called, even when 20 or more calls were attempted. 
Table I. Sampled Telephone Numbers Resulting in Contact with an Answering Machine or Combination of Answering Machine and No Answer

\begin{tabular}{lccc}
\hline & & & \\
& $\mathrm{N}^{\mathrm{a}}$ & \% Total & $\begin{array}{c}\text { \% Estimated } \\
\text { Households }^{\mathrm{c}}\end{array}$ \\
\hline November 1989 & 20 & 1.5 & 2.2 \\
March 1990 & 26 & 1.4 & 2.1 \\
September 1990 & 26 & 1.4 & 1.9 \\
October 1990 & 51 & 1.1 & 1.6 \\
April 1991 & 37 & 1.8 & 2.7 \\
October 1991 & 39 & 2.2 & 2.9 \\
November 1991 & 11 & .9 & 1.2 \\
April 1992 & 39 & 2.4 & 3.1 \\
November 1992 & 47 & 2.8 & 3.6 \\
\hline
\end{tabular}

\footnotetext{
${ }^{a}$ Number of all sampled phone numbers that resulted in an answering machine disposition on each attempt or a combination of answering machine and "no answer" dispositions.

${ }^{\mathrm{b}}$ Percentage of all sampled numbers that resulted in an answering machine disposition on each attempt or a combination of answering machine and "no answer" dispositions.

"In calculating the "\% estimated households," the proportion of "never answered" numbers estimated to be households (rather than "ring no answer" numbers) was assumed to be the same as that for those numbers for which a household determination was made.
}

also been an increase-from 38 percent to 48 percent-in the percentage of people indicating that someone in the household sometimes uses the device to screen calls. Since total call screening is a product of these two variables, it rose during this period from 9 percent to 19 percent. While these numbers are relatively large in comparison to the small percentage of households where consistent answering machine use was found, they are tempered by the broad scope of the question, "Does anyone in your household ever use this telephone answering machine to screen unwanted calls?" Obviously such screening was not occurring all the time, or we would never have reached them. ${ }^{4}$

The finding of little change in the percentage of households in which a telephone answering machine is consistently encountered seems somewhat in conflict with the report of significant increases in the proportion of households with answering devices and in the percentage of such households that use these devices to screen unwanted calls. 


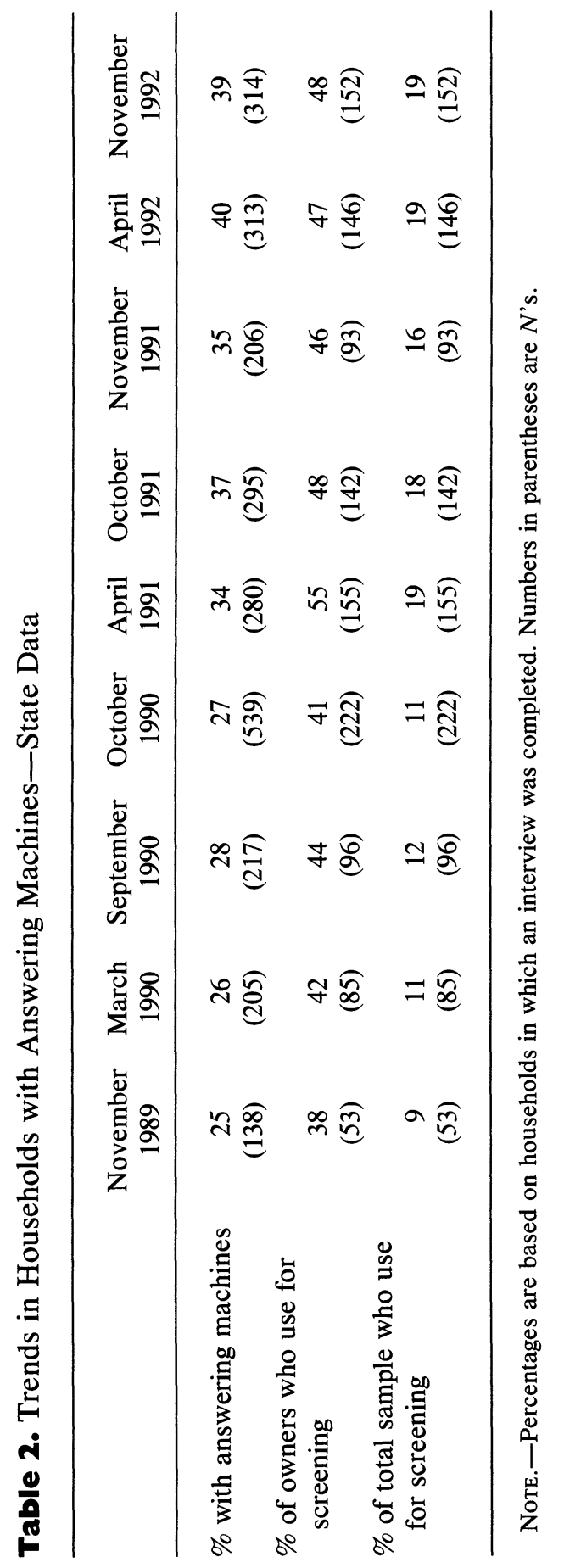


While these concepts are related, they are distinguished in that the former reports on recent telephone survey experience in encountering the answering machine barrier while the latter estimates the size of the potential barrier.

\section{Demographic Correlates of Ownership and Screening}

Pooling across the nine surveys, table 3 shows the relationship of six background variables to answering machine ownership and to use of the machine for call screening. ${ }^{5}$ In examining these data it should be kept in mind that our questions measure incidence and use at the household level. It is not appropriate, therefore, to infer that the individual-level characteristics described here are directly related to answering machine ownership or the use of such devices to screen calls. Rather, this analysis indicates the individual characteristics of those living in households that (1) have an answering machine and (2) use it for screening.

The data indicate that family income is significantly correlated with ownership. Ownership is much more prevalent among those with higher incomes, and the percentage of households with answering machines increases steadily across income groups.

Urbanicity also was significantly related to ownership. Suburbanites were most likely to report having an answering machine, followed by those living in urban areas.

Turning to characteristics of individuals living in households with a telephone answering machine, education, age, and race each show significant relations with ownership. Higher educated individuals, particularly those with at least some college, more often reported an answering machine in their household. Similarly, both younger respondents and whites were more likely to report an answering machine.

While these differences in answering machine ownership across subgroups are important, a more critical consideration from a survey research perspective is the extent to which such devices are used to screen calls. With the exception of age, however, these variables are

5. The data are pooled since the relations between these characteristics and answering machine ownership did not change over time. Given the large number of cases in this pooled data set, all the reported relationships were statistically significant at the .0001 level. More important, the relationship between answering machine ownership and total family income, urbanicity, education, and age was significant at the .001 level in each of the nine surveys. The relationship between ownership and race was significant at the .001 level in seven of the nine surveys; it was significant at the .01 level in November 1991 and not significant $(p>.05)$ in September 1990. The relationship between answering machine ownership and household size was not significant at the .01 level in any of the surveys. Data for the individual surveys are available from us on request. 
Table 3. Demographic Correlates of Telephone Answering Machine Ownership and Use for Screening Calls

\begin{tabular}{|c|c|c|c|}
\hline & $\begin{array}{c}\% \text { with } \\
\text { Answering } \\
\text { Machine }\end{array}$ & $\begin{array}{c}\% \text { Who } \\
\text { Use to } \\
\text { Screen } \\
\text { Calls }\end{array}$ & $N$ \\
\hline Total sample & 31 & 14 & 7,649 \\
\hline \multicolumn{4}{|l|}{ Household characteristics: } \\
\hline Under $\$ 15,000$ & 15 & 6 & 1,600 \\
\hline$\$ 15,000-29,999$ & 30 & 14 & 2,021 \\
\hline$\$ 30,000-49,999$ & 40 & 19 & 1,680 \\
\hline$\$ 50,000$ and over & 54 & 25 & 1,197 \\
\hline \multicolumn{4}{|l|}{ Household size: } \\
\hline One & 29 & 15 & 1,157 \\
\hline Two & 34 & 16 & 1,919 \\
\hline Three & 38 & 19 & 1,168 \\
\hline Four or more & 32 & 14 & 1,647 \\
\hline \multicolumn{4}{|l|}{ Urban/rural area: } \\
\hline Urban & 33 & 16 & 1,476 \\
\hline Suburban & 43 & 20 & 1,696 \\
\hline Rural & 26 & 12 & 2,031 \\
\hline \multicolumn{4}{|l|}{ Individual characteristics: } \\
\hline \multicolumn{4}{|l|}{ Education: } \\
\hline Less than high school diploma & 16 & 5 & 1,772 \\
\hline High school diploma & 25 & 11 & 2,600 \\
\hline Some college & 38 & 18 & 2,005 \\
\hline College degree & 49 & 23 & 1,540 \\
\hline \multicolumn{4}{|l|}{ Age: } \\
\hline $18-29$ & 36 & 18 & 2,389 \\
\hline $30-44$ & 38 & 19 & 2,206 \\
\hline $45-64$ & 30 & 12 & 1,966 \\
\hline 65 and over & 11 & 2 & 1,049 \\
\hline \multicolumn{4}{|l|}{ Race: } \\
\hline Blacks & 19 & 9 & 2,182 \\
\hline Whites & 36 & 16 & 5,661 \\
\hline
\end{tabular}


not significantly related to screening calls among those households with answering machines (data not shown). ${ }^{6}$ Thus to the extent that call screening is related to background characteristics (see table 3), it is mainly due to the higher incidence of answering machine ownership among certain groups rather than to differences between groups in likelihood of screening. ${ }^{7}$

Returning to the question of the subgroups that are most likely to be missed due to the use of answering machines as screening devices, table 4 shows the joint effect of education and age on answering machine ownership and screening. ${ }^{8}$ Cell entries are the deviations from the overall percentage of the sample using an answering machine to screen calls (14 percent). A positive figure means the group is more likely to screen calls, while a negative entry means a group is less likely to screen.

Within each age group, those with some college or a college degree were more likely than those with less education to screen calls. Moreover, within each of these education groups, younger respondents were generally more likely than older respondents to screen calls. Thus answering machine screening is a larger potential obstacle among certain subgroups, particularly younger, more educated respondents. Piazza (1993) reports a similar finding with respect to education.

\section{Conclusions}

This analysis provides a mixed message for survey research. The 2-3 percent of households that may regularly use answering machines to screen calls do not now represent a serious threat to the representativeness of telephone survey samples. On the other hand, both answering machine ownership and the use of these devices for at least some call screening increased consistently over the 3-year period of this study. The potential threat to representativeness is, therefore, also increasing.

Incidence of answering machine use and screening is also greater among certain subgroups of the population. Those with higher family incomes and more education, younger people, whites, and those living

6. Significant differences across age groups were noted in three of the nine surveys, with these differences largely a result of a much lower incidence of screening among those 65 and older.

7. The relationships between these characteristics and use of answering machines for screening did not change over time.

8. Education and age were chosen on the basis of a multivariate logit analysis, which identified them as the most important factors affecting answering machine ownership and call screening. This analysis is available from us on request. 
Table 4. Age and Education Subgroups Most Likely to Screen for Unwanted Calls

\begin{tabular}{lrrrrr}
\hline & \multicolumn{5}{c}{ Age } \\
\cline { 2 - 6 } Education & $18-29$ & $30-39$ & $40-49$ & $50-59$ & $60+$ \\
\hline Less than high school & -6 & -5 & -8 & -5 & -12 \\
High school degree & 0 & 0 & -2 & -4 & -10 \\
Some college & +7 & +8 & +6 & +1 & -9 \\
College degree & +17 & +12 & +10 & +8 & -8 \\
\hline
\end{tabular}

Note.-Figures represent the percentage above or below the total sample percentage of 14 percent. The smallest number of cases in any cell is 171 (those age 40-49 with less than a high school education).

in nonrural areas are more likely to own a telephone answering machine and to screen calls. (We should note that the population on which this analysis is based does not include any very large metropolitan areas, where use of telephone answering devices for screening may be higher.)

Strategies suggested by previous studies, such as repeated calls or leaving messages on answering machines, may become less effective as the incidence of these machines and their use for screening calls becomes more widespread. Thus survey researchers need to track not only the incidence of answering devices and the demographic factors associated with screening, but also the effects that strategies such as leaving various types of messages have on reaching the answering machine generation.

\section{References}

Baumgartner, Robert M. 1990. "Telephone Answering Machine Messages and Completion Rates for Telephone Surveys." Paper presented at the annual meeting of the American Association for Public Opinion Research, Lancaster, PA.

Electronic Industries Association. 1991. Consumer Electronics U.S. Sales. Electronic Industries Association, Washington, DC.

Oldendick, Robert W. 1993. "The Effect of Answering Machines on the Representativeness of Samples in Telephone Surveys." Journal of Official Statistics 9:663-72.

Oldendick, Robert W., George F. Bishop, Susan B. Sorenson, and Alfred J. Tuchfarber. 1988. "A Comparison of the Kish and Last Birthday Methods of Respondent Selection in Telephone Surveys." Journal of Official Statistics 4:307-18.

$\rightarrow$ O'Rourke, Diane, and Johnny Blair. 1983. "Improving Random Respondent Selection in Telephone Surveys." Journal of Marketing Research 20:428-32. 
Parsley, Teresa. 1992. "Prevalence and Use of Answering Machines: Data from a Nationwide Telephone Survey." Paper presented at the Field Directors and Field Technologies Conference, St. Petersburg, FL.

$\rightarrow$ Piazza, Thomas. 1993. "Meeting the Challenge of Answering Machines." Public Opinion Quarterly 57:219-31.

Piekarski, Linda. 1990. "Answering Machine Households Not So Elusive." The Frame 13:1.

$\rightarrow$ Tuckel, Peter S., and Barry M. Feinberg. 1991. "The Answering Machine Poses Many Questions for Telephone Survey Researchers." Public Opinion Quarterly 55:200-217. 